\title{
MACULAR PIGMENT OPTICAL DENSITY IN TYPE 2 DIABETES AND NORMAL CONTROLS; CORRELATION WITH VITAMIN D LEVELS
}

Neslihan Bayraktar Bilen ${ }^{1}$, Derya Koseoglu² ${ }^{2}$ Eda Demir Onal ${ }^{2}$, Defne Kalayci ${ }^{1}$, Dilek Berker ${ }^{2}$

Ankara Numune Education and Research Hospital, Department of Ophthalmology

${ }^{2}$ Ankara Numune Education and Research Hospital, Department of Endocrinology and Metabolism

\section{AlM}

To compare macular pigment optical density (MPOD) in diabetic and non-diabetic patients by using heterochromatic flicker photometry and to investigate the correlation of MPOD with glycosylated hemoglobin (HbA1C), serum lipid levels and vitamin $D$ levels.

\section{METHODS}

Sixty-seven patients with 10/0 visual acuity were divided into group 1 (controls, n:35) and group 2 (diabetics without retinopathy, n: 32). MPOD was measured with a heterochromatic flicker method and compared between groups. Diabetes duration, smoking status, HbA1c and serum lipid levels and body mass index were recorded for each patient. The correlation of $\mathrm{HbA} 1 \mathrm{C}$, serum lipid (HDL, LDL, total cholesterol, and triglycerides) and vitamin D levels with MPOD were analyzed in both groups.

\section{RESULTS}

The mean $( \pm S D)$ age in group $1(48.74 \pm 1.568)$ and group $2(51.59 \pm 1.527)$ were statistically similar $(p>$ $0.05)$. Mean MPOD was not significantly different between group $1(0.5589 \pm 0.02183)$ and group $2(0.5716 \pm$ $0.023)(p>0.05)$. No significant correlations were found between MPOD and HbA1C, serum lipid levels or vitamin $D$ levels in both groups ( $p>0.05)$.

\section{CONCLUSIONS}

Type 2 diabetic patients without retinopathy had not reduced MPOD when compared with non-diabetic patients. No correlation was found between MPOD, HbA1C, serum lipid levels and vitamin D levels. 